\title{
Pós-graduação em Saúde Coletiva no Brasil: Histórico e Perspectivas
}

EVERARDO DUARTE NUNES*

O presente trabalho aborda a constituição do campo da Saúde Coletiva no Brasil em três aspectos: origens da Saúde Coletiva, aspectos históricos da saúde no Brasil, a Saúde Coletiva como prática pedagógica e perspectivas do campo. A noção básica que orienta a elaboração deste trabalho é a que considera a Saúde Coletiva como um campo, dentro da concepção dada a essa noção por Pierre Bourdieu. São trazidas informações sobre a situação dos cursos de pós-graduação e da estrutura curricular. Nas conclusões, demarcase a posição de entender a Saúde Coletiva como um campo que se baseia na interdisciplinaridade e que se apóia nas dimensões quantitativas e qualitativas, sincrônicas e diacrônicas, objetivas e subjetivas.

Palavras-chave: Saúde Coletiva, história; Saúde Coletiva, prática pedagógica; Saúde Coletiva, estrutura curricular.

Recebido em 24/05/2005.

Aprovado em 13/06/2005. 


\section{Introdução}

Abordar a prática pedagógica que se instituiu em torno da Saúde Coletiva significa também entender como foi definido esse campo e como se estruturaram suas práticas teóricas. Embora cada um deles constitua um subcampo com características próprias, em nosso entendimento a Saúde Coletiva vem-se organizando na interface do que denominamos as dimensões do pensamento, da teoria e do movimento, que se traduzem em uma forma de entender a saúde, pesquisá-la teoricamente e institucionalizá-la acadêmica, política e pedagogicamente. Embora não seja possível num único artigo abordar todos esses aspectos, há necessidade de tangenciá-los, a fim de que se construa um pano de fundo no qual a história e as perspectivas da pós-graduação se evidenciem em toda sua pujança e criatividade.

\section{Notas sobre as Origens da Saúde Coletiva}

Desvendar as origens e a composição interna, assim como as práticas de ensino e científicas que circundam a Saúde Coletiva, é tarefa complexa; supõe retomar a história e a epistemé e rever como o conhecimento pesquisado foi, e vem sendo, transmitido. Interessante lembrar que recuperar a história e desvendar sua composição interna (epistemé) tem sido uma das preocupações presentes em diversos trabalhos e análises que vêm acompanhando a própria construção da Saúde Coletiva no Brasil. Esse esforço tem estado presente desde os anos 80 e se estende até a atualidade, buscando fornecer os elementos que configurem nossa identidade e revelem quem somos, onde nos situamos, $o$ que fazemos, quais os produtos das nossas práticas.

De forma geral, pode-se dizer que a dificuldade para definir esse campo se situa, dentre outros, no fato de ser uma criação que transborda os limites disciplinares e que se apresenta na interface de áreas do conhecimento detentoras de especificidades teóricas e conceituais, procedentes das ciências biológicas, sociais, matemáticas, epidemiológicas e das humanidades que foram elaboradas ao longo dos séculos, no marco da cientificidade para o estudo da realidade cósmica e humana. Podemos dizer que a Saúde Coletiva é uma criação da pós-modernidade, embora com raízes fincadas no século XIX, e paradoxalmente, inicia sua prática discursiva tomando, nos anos 70, o modelo teórico do materialismo histórico, no momento em que se discutia a validade da grande narrativa para explicar os fenômenos humanos e sociais. 
Nossa perspectiva de análise baseia-se em Bourdieu (1983) e sua teoria de campo, que não detalharemos neste momento. Lembramos apenas que, para Bourdieu (1983), campo é o locus onde se trava uma luta concorrencial entre os agentes em torno de interesses específicos que caracterizam a área em questão. Nesse espaço se manifestam as relações de poder que visam, por meio da concorrência, a obter um capital simbólico. O campo estrutura-se a partir da distribuição desigual de um quantum social (capital social), que determina a posição que um agente específico ocupa no seu interior. Ponto a ser ressaltado é o que se refere à idéia de que os diferentes campos sociais se organizam em torno de objetivos e práticas específicas, e apresentam uma lógica de fundamento próprio, que estrutura as relações entre os agentes em seu interior. Como cada campo possui uma forma dominante de capital, que se constitui através de conceitos que adquirem status de valores, que orientam inclusive o pertencimento a esse campo, é interessante tomá-lo como referência para a nossa análise ${ }^{1}$.

Como afirmamos, nos últimos anos muitos se debruçaram sobre esse campo, a fim de desvendá-lo. Nossos trabalhos anteriores sobre a história da Medicina Social (NUNES, 1980), das contribuições das Ciências Sociais para o campo da Saúde Coletiva (NUNES, 1991), sobre a interdisciplinaridade e a Saúde Coletiva (NUNES, 1995), sobre o conceito de Saúde Coletiva (NUNES, 1994) somam-se a outros que têm evidenciado a importância do campo e sua marcante presença na área da Saúde. Dentre trabalhos recentes, citamos: Burlandy (1993), Campos (2000), Paim e Almeida Filho (1998) e Belisário (2002).

$\mathrm{Na}$ recuperação historiográfica da Medicina Social, deve-se citar a conhecida conferência que Michel Foucault pronunciou no Rio de Janeiro, em outubro de 1974, "As origens da Medicina Social", na qual toma como pressuposto que "a medicina moderna é uma medicina social que tem como background uma certa tecnologia do corpo social; que a medicina é uma prática social que somente em um dos seus aspectos é individualista e valoriza as relações médico-paciente" (FOUCAULT, 1979, p. 79).

$\mathrm{O}$ autor prossegue:

"com o capitalismo não se deu a passagem de uma medicina coletiva para uma medicina privada, mas justamente o contrário; que o capitalismo, desenvolvendo-se em fins do século XVIII e início do século XIX, socializou um primeiro objeto que foi o corpo enquanto força de produção, força de 
trabalho. [...] Foi no biológico, no somático, no corporal que, antes de tudo, investiu a sociedade capitalista. O corpo é uma realidade biopolítica. A medicina é uma estratégia biopolítica" (FOUCAULT, 1979, p. 80).

Com bases nessas hipóteses, reconstitui as origens da Medicina Social, na Alemanha, onde ela assume as características de "policia médica"; na França, de "medicina urbana" e, na Inglaterra, de "medicina da força de trabalho". O estudo da morbidade, do controle, da normalização da prática e saber médicos, do controle dos espaços e instituições urbanas e da circulação dos elementos (água e ar), do controle dos pobres e depois dos trabalhadores, para torná-los mais aptos ao trabalho e menos perigosos, marcaram em suas origens a medicina social européia, refletiram-se na organização das práticas sociais e coletivas de saúde e se expressaram na higiene social, na salubridade, na saúde pública de muitos países. Essas idéias nos levam a situar que a expressão Medicina Social foi cunhada pelo médico francês Jules Guérin, em 1848, num texto denominado "Médicine Sociale", publicado no La Gazette Médicale de Paris, no dia 11 de março. Nesse texto, Guérin escreve:

"Em lugar de aplicações vacilantes e isoladas agrupadas em títulos como polícia médica, higiene pública ou medicina legal, chegou a hora de reunir estes fatos dispersos, regularizá-los em um todo e de levá-los à sua significação mais elevada, sob o nome, mais apropriado para suas funções, de medicina social” (GUÉRIN, 1848, p. 183).

Deve-se lembrar que as idéias de reforma médica que aparecem tanto na França como na Alemanha fazem parte de um contexto marcado por movimentos revolucionários, que enfatizavam a democracia e a reforma da sociedade.

Se, na França, o conceito evidencia uma proposta de assegurar o monopólio da profissão médica sobre o saber e prática da medicina, na Alemanha, Neumann e Virchow são enfáticos quando afirmam:

"a ciência médica é intrínseca e essencialmente uma ciência social e, até que isto não seja reconhecido na prática, não seremos capazes de desfrutar seus benefícios e teremos que nos contentar com um vazio e uma mistificação" (ROSEN, 1963, p. 35-36).

Como se sabe, o processo de medicalização não iria se esgotar com o 
grande projeto de "medicina social" de 1848, mesmo porque, como analisa Hobsbawn (1979, p. 43), "as revoluções de 1848 surgiram e quebraram-se como uma grande onda, deixando pouco exceto mito e promessa", legaram questões fundamentais como a questão operária, marcaram o fim da política da tradição, das monarquias e da regra do direito divino na sucessão das dinastias e colocaram, como vimos, em evidência, a saúde.

Se, na segunda metade do século XIX, assiste-se a um processo de valorização do social, é também nesse momento que se inicia um forte encaminhamento das práticas médicas com hegemonia de um modelo que será fruto das descobertas de Pasteur, a partir de 1860, e que inaugura a "revolução científica" na medicina. A partir dessa data, a descoberta dos agentes etiológicos imprime outra feição à compreensão do processo da doença. Lembre-se que a institucionalização da Medicina Social, idealizada na metade do século XIX, iria ocorrer em 1881, em Munique, com a criação do primeiro curso de Medicina Social. E, já no século XX, os cursos de Harvard, em 1913, Johns Hopkins, em 1916; o do "Laboratório de Higiene", junto à Faculdade de Medicina e Cirurgia, em São Paulo, em 1918, oficializado pelo governo do estado, em 1925, adquiriu autonomia, deixando de ser dependência direta da Faculdade de Medicina e sendo denominado Instituto de Higiene de São Paulo.

Para Salomon-Bayet (1986, p. 12), a revolução biomédica suscitada pelos trabalhos de Pasteur pode ser denominada de "la pastorization de la médecine", que a distingue de "la pasteurization de la médecine", no sentido de que ela significa, de um lado, uma revolução teórica, e, de outro, a medicalização de uma sociedade, legislando sobre a saúde pública, institucionalizando o ensino e atuando no plano político e social. Sem dúvida, as descobertas dos microorganismos serão da maior importância para a saúde pública, especialmente quando, além da relação indivíduo-agente, se estabelece um modelo epidemiológico como uma interação entre esses dois elementos e o ambiente. Esse foi o modelo básico da saúde pública a partir das últimas décadas do século XIX. Bem mais tarde é que o modelo sobre a doença, da teoria microbiana, ampliado no modelo ecológico, seria alvo de críticas. Suas insuficiências são conhecidas: de um lado, não dava conta de explicar as doenças crônicas e, de outro, com o advento da psiquiatria, colocava-se em evidência que muitas doenças tinham causas psicológicas.

Nesse cenário irá ocorrer um recrudescimento no estudo dos aspectos sociais na medicina e na saúde. Na Era Pós-germe, ou, como a denominam 
Susser e Susser (1996), na Era da Epidemiologia das Doenças Crônicas, a perspectiva de análises com base nas Ciências Sociais será retomada, como também, a presença de novos modelos para os estudos epidemiológicos. Estes podem ser de Morris, Chen, Dever, McKeown, ou dos latino-americanos, da chamada Epidemiologia Crítica. Com diferentes ênfases, irão salientar determinantes sociais, ecológicos, políticos, da organização do sistema de saúde, como no caso de Alan Dever, epidemiologista americano que nos anos 70 aplicou o modelo de "campo de saúde" proposto por Laframboise em 1973, posteriormente utilizado pela política de saúde canadense. Segundo esse modelo, a saúde é determinada por um conjunto de fatores agrupáveis em quatro categorias: a biologia humana, o ambiente, o estilo de vida e o sistema de atenção à saúde.

Dever trabalhou com dados relativos ao estado da Geórgia e aos Estados Unidos como um todo, a fim de verificar qual era a contribuição de cada componente quando se analisavam as taxas específicas de mortalidade por doença e por grupo etário, tendo encontrado os seguintes resultados, em ordem decrescente: estilo de vida (43\%), biologia humana (27\%), ambiente (19\%) e serviços de saúde (11\%). Para os mesmos componentes, encontrou as seguintes proporções de gasto federal em saúde: estilo de vida (1,2\%), biologia (7\%), ambiente $(1,5 \%)$ e serviços de saúde (91\%) (CARVALHO, 1996) ${ }^{2}$.

Já estamos no século XX e há, ainda, contribuições importantes trazidas para o campo da Saúde, procedentes dos estudos sociológicos relacionando os fatores sociais para o estudo da doença, como as realizadas nas primeiras décadas do século - as da Escola de Chicago, nos anos 20, e os estudos de comunidades; a análise da prática médica de Parsons, dos anos 50; os avanços das teorias interacionistas e dos estudos marxistas, dos anos 70. Data desse período o início da grande contribuição trazida pelos estudos latino-americanos. As contribuições das Ciências Sociais têm sido da maior importância para a área da Saúde, pela diversidade temática abordada e pluralidade teórica assumida em décadas recentes. Perlin $(1992, \text { p. } 33)^{3}$, ao analisar a Sociologia, observa:

"As linhas cruzadas que cobrem a face da Sociologia na atualidade refletem, naturalmente, a especialização de interesses importantes que têm emergido gradualmente em recentes anos, os refinamentos de perspectivas teóricas, e o desenvolvimento de metodologias sofisticadas".

E estas serão apreendidas pela Sociologia da Saúde. Salienta que, na 
atualidade, não se justifica uma visão teórica particularista, mas que a pluralidade teórica e metodológica somente poderá concorrer para que o campo continue a trazer sua contribuição para os problemas de saúde e da organização de suas práticas.

\section{Da Higiene à Saúde Coletiva no Brasil}

Num sentido geral, as fases apontadas anteriormente também irão aqui ocorrer. Anterior à teoria do germe, pode-se constatar que, até as primeiras décadas do século XX, a medicina estende-se sobre a sociedade como um poder disciplinar, recaindo suas ações (ou intenções) sobre a higienização e medicalização do espaço urbano.

O período que vai de 1870 até 1930 será atravessado por várias conjunturas, que vão desde a presença dos intelectuais empenhados na formulação dos discursos científicos e políticos, até à do papel de instituições, como o da Academia Nacional de Medicina, lutando pela universalização da atenção médica de caráter clínico e o do Estado, com um modelo de saúde pública, com base na ciência e na ação de Oswaldo Cruz. Inaugura-se a organização da Saúde Pública em moldes científicos calcados na Bacteriologia e Microbiologia. Em São Paulo, a figura de Emílio Ribas será relevante nos primeiros empreendimentos de higiene pública, tanto no combate às endemias e epidemias que ameaçavam as áreas cafeeiras do estado de São Paulo, como dando início ao saneamento do porto de Santos. O modelo, denominado bacteriológico-campanhista, encontraria sua primeira reformulação no que ficou designado como modelo médico-sanitário, inaugurado por Paula Souza, vinculando o projeto de saúde às ações educativas realizadas por meio dos Centros de Saúde.

Numa rápida revisão do período que se estende pelas três primeiras décadas do século $\mathrm{XX}$, devem ser citados alguns fatos que se tornaram marcantes: a Lei de Indenização dos Acidentes de Trabalho (1919); a criação do Conselho Nacional do Trabalho (1922); e a Lei Elói Chaves (1923). Como salienta Luiz Antônio de Castro Santos, com muita propriedade, não se pode deixar de citar como evento da maior importância a Reforma Carlos Chagas. Chagas foi encarregado pelo presidente Epitácio Pessoa de elaborar um novo Código de Saúde Pública. O novo regulamento, uma segunda reforma sanitária, foi aprovado em 1919 e entrou em vigor a partir de 1920. Criava o Departamento 
Nacional de Saúde Pública (DNSP), em substituição à antiga Diretoria Geral de Saúde Pública (DGSP), responsável pelos serviços sanitários terrestres, marítimos e fluviais e pelos serviços de profilaxia rural (COC/FIOCRUZ, 2005).

Mas foi a partir de 1930 que se iniciou a constituição das políticas sociais de caráter nacional. Emblematicamente, há um fato que talvez ilustre esse momento: a criação, em 1930, do Ministério de Educação e Saúde, como evento político-sanitário, centralizando a política de saúde, com a retomada das campanhas sanitárias. Muitos são os estudos que procuraram analisar a saúde pública no Brasil até a Primeira República, sendo que, para os períodos posteriores, há alguns estudos importantes: Braga e Paula (1981) apontam, dentre outros fatos, o caráter restritivo que teve a política de saúde em sua amplitude de cobertura; Yida (1988) analisa a saúde pública como parte integrante da formação de um estado burguês; Mehry (1992), analisando o período de 1920-1948, realiza uma leitura das políticas governamentais como modelos tecnoassistenciais, vinculando-as às correntes tecnológicas do campo sanitário e às questões políticas mais amplas. Destaque-se, dentre os estudos, o livro de Luz (1982), que analisa a trajetória de importantes instituições médicas no Brasil, de meados do século XIX até início do século XX, com a preocupação de verificar as relações entre a medicina e a constituição do Estado Nacional brasileiro.

Os anos 60 e 70, especialmente a partir de 1964, até 1974, serão caracterizados por um Estado centralizador e burocratizado, num regime fortemente autoritário. A redemocratização seria para a segunda metade dos anos 70 e, como se sabe, de forma lenta e gradual, e somente em 1988 seria promulgada a nova Constituição Federal. Dois anos antes, em 1986, com a presença de cerca de 4.000 participantes, a VIII Conferência Nacional de Saúde propunha a organização do Sistema Único de Saúde e, efetivamente, no ano seguinte, 1987, é aprovado o SUDS (Sistema Unificado e Descentralizado de Saúde).

Em 1988, a Constituição estabelece o SUS como nova formulação política e organizacional para o reordenamento dos serviços e ações de saúde, norteada por três princípios - a universalidade, a eqüidade e a integralidade -, que seria regulamentada pela Lei $\mathrm{n}^{\circ}$ 8.080/90, de 1990, estabelecendo a descentralização político-administrativa como forma de efetivar a implantação do sistema. 
Adiantamos alguns momentos da história, mas é preciso voltar aos anos 70, pois foi nessa década que o projeto de construir o que se denominaria de Saúde Coletiva começou a se institucionalizar.

Após o longo período que se estendeu pelos anos 50 e 60 , com o projeto preventivista e da medicina social, especialmente através dos departamentos de Medicina Preventiva e Social, assume-se que a formação de recursos humanos para a área da Saúde Pública deveria voltar-se não somente para a capacitação de técnicos, especialistas e residentes, mas adensar essa formação em níveis acadêmicos que levassem à obtenção de títulos de mestre e doutor, voltados para pesquisa e docência. Lembre-se que, nesse momento, vivia-se o impacto da Reforma Universitária de 1968, de um lado, e, de outro, toda a crítica que se estabelece ao modelo médico hegemônico, assim como se discutiam as diferenças entre medicina preventiva, medicina social e saúde pública. O trabalho de Arouca (1975) é fundamental nesse redimensionamento do campo, como também o de Donnângelo (1975), do mesmo ano, sobre o mercado profissional médico. Os próprios órgãos internacionais, como a Organização Pan-Americana da Saúde, assumem posição crítica em relação ao campo da Medicina Social. O documento da Segunda Reunião do Comitê do Programa de Livros-Textos da OPS/OMS para o Ensino da Medicina Preventiva e Social, realizada em 1974, assinala:

\footnotetext{
“Anteriormente, a preocupação radicava em preparar um médico que estivesse capacitado para 'ver' o doente de forma integral. Para isto a medicina preventiva desenvolveu programas de ensino tendentes a formar no profissional uma mentalidade 'preventiva' e chamou a atenção sobre os aspectos biopsicossociais das doenças. Agora trata-se de que a medicina social estude as instituições que proporcionam atenção de saúde e os esquemas de ação médica que delas resultam. Isto permitirá ao futuro profissional ter clara consciência do resultado de sua atividade dentro do contexto social em que se localizará" (OPAS/OMS, 1976).
}

Outro trabalho marcante do final dos anos 70 é a obra coletiva $A$ danação da norma, de Machado et al. (1978), uma "história dos saberes" que mostra as origens da Medicina Social e a constituição da Psiquiatria no Brasil. A esse trabalho junta-se o de Luz (1979), fundamental para a compreensão das instituições médicas no Brasil como estratégia de poder. Muitas das questões que seriam retomadas ao longo dos anos 80 já se definiam na 
segunda metade dos anos 70, a fim de se entender

"o estudo da dinâmica do processo saúde-doença nas populações, suas relações com a estrutura de atenção médica, bem como das relações de ambas com o sistema social global, visando à transformação destas relações para a obtenção, dentro dos conhecimentos atuais, de níveis máximos possíveis de saúde e bem-estar das populações" (AROUCA, 1975, p. 141).

Ao citar os trabalhos acima, não se pode deixar de lembrar que os anos 70 foram dos mais férteis em discussões teóricas sobre as relações saúdesociedade, não apenas pela presença marcante do paradigma marxista, mas de outros referenciais, como o estruturalismo de Foucault, e as discussões sobre a antipsiquiatria, com Basaglia, Cooper, Laing e Castel.

Mas a presença de forte repressão política e de piora crescente nos indicadores socioeconômicos e de saúde punham sob suspeita um modelo de saúde pública desenvolvimentista, que havia postulado que um dos efeitos do crescimento econômico seria a melhoria das condições de saúde. Autores como Laurell (1986) apontam que, frente à desnutrição, aos acidentes de trabalho e às doenças crônico-degenerativas, a América Latina apresentava um perfil de morbi-mortalidade que abarcava o pior dos mundos, como uma mescla de patologia da pobreza e da patologia da riqueza. Quando se analisa retrospectivamente esse período, fica nítido que, na emergência de uma proposta para a saúde, associavam-se perspectivas teóricas, tentando superar a unicausalidade e a biologização do conhecimento, extremamente firmado na linha de um saber positivista; perspectivas trazidas pelos movimentos populares e de pensar o planejamento em saúde como questão política e não exclusivamente técnica.

Como já assinalamos, uma das formas encontradas para a realização desse programa foi através dos cursos de pós-graduação, que trataremos mais detalhadamente em outro ponto deste artigo. Neste momento, citamos algumas datas que são marcos na história dessa institucionalização: 1970, na Faculdade de Saúde Pública da USP; 1971, na Faculdade de Medicina de Ribeirão Preto; 1973, na Faculdade de Medicina da USP e na Faculdade de Medicina da UFBa; 1974, no Instituto de Medicina Social da UERJ. Não menos importante foi a criação dos cursos regionalizados de Saúde Pública, em 1970 e, no final dos anos 70, da regulamentação da Residência em Medicina Preventiva. 
O final dos anos 70 é marcado pelo agravamento da crise econômica e, frente aos problemas de saúde, lança-se em nível internacional o projeto da Atenção Primária e, em nível nacional, a necessidade de uma tomada de posição frente ao problema sanitário, quando aparecem dois importantes espaços de resistência e análise crítica da situação: o CEBES, criado em 1976, e a ABRASCO, em 1979. Como assinalamos anteriormente, estávamos ainda a quase uma década de distância de um fato que seria marcante para a história da Saúde Coletiva: a realização da VIII Conferência Nacional de Saúde, que problematizou e redefiniu a saúde, considerando-a como resultado das condições de existência de uma sociedade determinada, como direito de todos e dever do Estado.

Cronologicamente, instala-se a terceira fase da trajetória do que se pretendia com o estudo das relações saúde-sociedade: a fase da Saúde Coletiva. Basicamente, pretendia-se que as instituições formadoras de recursos humanos deveriam orientar-se na formação, considerando a importância de se estabelecer "um processo gerador de análise crítica do setor saúde na realidade social em que se insere [...] potencialmente capaz de influir no campo da docência, pesquisa e prestação de serviços" (ABRASCO, 1982, p. 113-114). Não se trata simplesmente de aglutinar diversos programas de ensino, mas de estruturar um campo de saber e prática, "para que sejam encontradas formas de atuação dirigidas à solução dos problemas da população brasileira".

As discussões que ocorreram ao longo dos anos 80 e 90 são de diversas naturezas. Numa situação cada vez mais carregada de dificuldades, as desigualdades sociais irão acentuar-se. Sem dúvida, como apontado pelos estudiosos, a iniqüidade será o maior saldo vermelho no balanço sócio-sanitário da humanidade, no final do milênio. Com a iniqüidade expressa numa concentração de renda cada vez maior e sua tradução na pobreza em cifras que se elevam continuamente, crescem a fome, a má nutrição e a desnutrição. Acrescente-se à violência que se expande e que gera a inseguridade social, o terceiro aspecto - a deterioração do ambiente. Com sérios problemas sociais e sanitários, somados à não-efetivação das reformas dos sistemas de saúde preconizados no final dos 80 , a pauta da Saúde Coletiva tornava-se mais extensa a cada dia que passava.

No início dos anos 90, frente à enorme crise mundial, que também se expressaria em uma crise da Saúde Pública, a Organização Pan-Americana da Saúde reuniu um grupo de especialistas para discutirem a questão. Em tese 
apresentada em 1993, Schramm (1993) analisa os documentos apresentados e, tomando como referência a questão da ética, assinala que para uns, como Badgley (1992), o fracasso das propostas se devia à falta de pragmatismo; para outros, como Ferreira (1992) e Macedo (1992), a saúde era explicitamente apontada, tanto como um compromisso da sociedade consigo mesma, quanto como uma questão de "dever ser", isto é, relativa a um "conjunto de valores" para o agir. Frenk (1992) e Terris (1992), sem desconsiderar a questão da ética, sublinham o aspecto epistemológico-metodológico - o caráter complexo -, apontando a mutidisciplinaridade e a relação lógica (medicina social/saúde pública). Testa (1992) discute o caráter da saúde do ponto de vista social e não meramente de aplicação das Ciências Sociais à saúde. Para Schramm (1993), a crise manifesta-se em inúmeros níveis, inclusive na dificuldade de mapeamento dos problemas e de uma cibernetização e virtualização da cultura, o que, de um lado, configura uma crise do simbólico e, de outro, de aniquilação do real, redundando em desequilíbrios, tanto ecológicos como relacionais.

Duas décadas e meia se passaram desde a criação da ABRASCO, mas isto não significa que tenha ocorrido um consenso acerca da conceituação da Saúde Coletiva. Como já assinalamos em trabalho anterior,

\footnotetext{
"mais do que ser conformada pelo somatório dos diversos programas das instituições formadoras que carregavam os seus referenciais preventivistas, de medicina social e de saúde pública, a Saúde Coletiva passa a se estruturar como um campo de saber e prática. $\mathrm{O}$ acúmulo de experiências e o exercício crítico e político estão nas bases dessa idéia que vai-se fortalecendo na medida em que encontra nas práticas teóricas o solo que a fundamenta" (NUNES, 1994, p. 16).
}

Torna-se interessante recuperar as diversas tentativas de definir a Saúde Coletiva, pois elas nos ajudam a situar a complexidade que envolve esse campo. Já nos anos 80, Teixeira (1985, p. 97) via a Saúde Coletiva como um campo de aplicação das Ciências Sociais, mas também escreveu que

"a matriz teórico-conceitual do Movimento Sanitário pode ser encontrada na delimitação de sua área de conhecimento, expressa na adoção do conceito de 'saúde coletiva', uma originalidade nacional face à heterogeneidade de denominações habituais, tais como saúde pública, medicina social, medicina preventiva, saúde comunitária (TEIXEIRA, 1988, p. 195). 
Segundo Birman (1991), a Saúde Coletiva não apenas estabelece uma crítica ao universalismo naturalista do saber médico, mas rompe com a concepção de saúde pública, negando o monopólio do discurso biológico.

Para Stotz (1997, p. 280-282), o campo da Saúde Coletiva vem sendo marcado por tensões epistemológicas, mas remete ao seu significado como um projeto científico, e o define como "um campo de conhecimento interdisciplinar, marcado pelas tensões epistemológicas". Para ele, também não é possível pensar em uma teoria unificadora que explique o conjunto de fenômenos e objetos de estudo.

Sem entrar na discussão das áreas constituintes da Saúde Coletiva, adiantamos que a questão de localizar seus elementos formadores levou alguns autores, como Carvalho (1997, p. 60), a afirmar que a Saúde Coletiva apresenta uma tradição intelectual, assim como sua institucionalização, distinta daquela que ocorreu nas Ciências Sociais.

"[A Saúde Coletiva] representou um esforço de qualificar problemas da saúde pela temática da 'modernização periférica' em voga nos anos 60 e 70, com a atenção voltada para a expansão dos aglomerados humanos nos grandes centros urbanos, a mudança nos padrões demográficos do mercado de trabalho, a intensificação da conflitividade social e as práticas de regulação desfechadas pelo Estado de Bem-estar Social, em sua fraca versão local. Seu comprometimento com as teorias e os métodos histórico-estruturais notadamente o materialismo histórico - completa o quadro de definição do novo campo de conhecimento, cujo 'principal desafio era, então, o de integrar o indivíduo, suporte singular da doença, aos processos coletivos'”.

Como conclusão dessas análises, diríamos que a Saúde Coletiva, como organização (que se expressa na ABRASCO), pode ser dimensionada, em suas origens, como um fato sociológico e político - nasce no embate das questões postas pela área da Saúde nos anos 70, no processo de institucionalização da formação de recursos humanos e dos conhecimentos que se encontravam dispersos nas escolas de saúde pública, departamentos de Medicina Preventiva e Social e nos primeiros cursos de Medicina Social e nos interesses de realizar pesquisas e produzir práticas políticas voltadas à melhoria das condições de saúde, caracterizando-se por ser um movimento contra-hegemônico visando a rever criticamente o modelo sanitário brasileiro, mas também dos interesses corporativos e associativos de destacada parcela da intelectualidade da saúde. 
Em recente trabalho, Paim e Almeida Filho (1998, p. 318) assinalam:

"o trabalho teórico-epistemológico empreendido mais recentemente aponta a Saúde Coletiva como um campo interdisciplinar e não propriamente como uma disciplina científica, muito menos uma ciência ou especialidade médica”.

Prosseguem, afirmando:

"A constituição da Saúde Coletiva, tendo em conta os seus fecundos diálogos com a Saúde Pública e com a Medicina Social, tal como vem-se concretizando nas duas últimas décadas, permite uma delimitação compreensivelmente provisória desse campo científico, enquanto campo de conhecimento e âmbito de práticas" (PAIM e ALMEIDA FILHO, 1998, p. 318).

\section{A Saúde Coletiva como Prática Pedagógica}

Dentro dessa temática, é interessante que se faça, mesmo de forma resumida, um retrospecto sobre a formação em Saúde Pública, a fim de que se entenda como se estruturou a Saúde Coletiva a partir dos anos 70. Belisário (2002, p. 40-42) elabora uma cronologia sobre essa formação, dizendo que ela se iniciou nos anos 20, com a instituição do curso de Higiene e Saúde Pública, "dirigido à formação de especialistas médicos para que atuassem nos serviços públicos de saúde, que passaram a ser denominados sanitaristas".

Cita, ainda, que em 1922 realizou-se, no Rio de Janeiro, o Congresso Nacional de Práticos, na qual se discutiram questões médicas, da saúde pública e do papel do Estado; e, em 1923, criou-se a primeira associação profissional a Sociedade Brasileira de Higiene (SBH). No ano seguinte, 1924, foi realizado o Segundo Congresso de Higiene, cuja principal reivindicação era a criação de uma Escola de Saúde Pública. Em 1925 foi criado o curso de Higiene e Saúde Pública, como uma especialização do ensino médico, junto ao Instituto de Higiene de São Paulo. Em 1929 foi diplomada a primeira turma de médicos sanitaristas, e em 1931 o Instituto foi reconhecido oficialmente como Escola de Higiene e Saúde Pública, passando em 1945 a constituir uma das unidades autônomas de ensino superior da Universidade de São Paulo, sob a denominação de Faculdade de Higiene e Saúde Pública; em 1969, passou a sua atual denominação, Faculdade de Saúde Pública.

Também as origens da Escola Nacional de Saúde Pública remontam 
ao ano de 1925, quando foi criado o curso Especial de Higiene e Saúde Pública, anexo à Faculdade de Medicina do Rio de Janeiro. Visava à formação de médicos voltados para as funções sanitárias, cabendo ao Instituto Oswaldo Cruz a responsabilidade técnica, administrativa e didática do referido curso. Em 1954, pela Lei $n^{\circ} 2.312$, de 3 de setembro, seria criada a Escola Nacional de Saúde Pública, que passou, em 1996, a integrar a atual Fundação Oswaldo Cruz. Nos anos de 1967 e 1968, a ENSP realizou três cursos de mestrado em Saúde Pública, interrompidos em 1969 e reabertos em 1977, sendo que o curso de doutorado foi aberto em 1980.

Acompanhando a evolução histórica dos cursos de pós-graduação stricto sensu, que se incluem na ampla denominação de Saúde Coletiva, verificase que é a partir dos anos 70 que se inicia a instalação dos primeiros cursos, sendo que a expressão "Saúde Coletiva" não era usada no início dos anos 70. Como já vimos, a idéia de organizar uma área denominada "Saúde Coletiva" foi tratada em dois momentos, no ano de 1978: no I Encontro Nacional de Pósgraduação em Saúde Coletiva, realizado em Salvador, Bahia e na Reunião Subregional de Saúde Pública da OPAS/ALAESP, realizada em Ribeirão Preto. A proposta era a criação de uma entidade que congregasse todos os cursos de pós-graduação dessa área. Em 27 de setembro de 1979, na I Reunião sobre a Formação e Utilização de Pessoal de Nível superior na área de Saúde Coletiva, realizada em Brasília, promovida pelos ministérios da Educação, Saúde, Previdência e Assistência Social e Organização Pan-Americana de Saúde, foi criada a ABRASCO.

Outros cursos pioneiros no Brasil foram os criados, em 1971, na Faculdade de Medicina da USP/Ribeirão Preto; em 1973, na Faculdade de Medicina da USP/SP; em 1973, na Faculdade de Medicina da UFBa; e, em 1974, o mestrado em Medicina Social do Instituto de Medicina Social da UERJ. Este último, como assinalam Bezerra Jr. e Sayd (1993, p. 5), "visava a formar um médico com conhecimentos nas áreas de Epidemiologia, Planejamento e Ciências Sociais de tal modo entrelaçados que lhe permitissem uma ação polivalente, crítica e transformadora". A ampliação desse curso, sob a denominação de Saúde Coletiva, data de 1987, sendo que em 1991 foi criado o doutorado. A proposta ampliou-se, também, no momento em que uma das áreas de concentração passou a incluir as Ciências Humanas e Sociais.

Em estudo realizado no final dos anos 90, constatava-se a existência de 33 cursos de pós-graduação sob a rubrica geral de Saúde Coletiva, sendo 23 
mestrados e 10 doutorados. Regionalmente, estavam assim distribuídos: Nordeste - 7 mestrados e 1 doutorado; Centro-Oeste - 2 mestrados e 1 doutorado; Sudeste - 11 mestrados e 7 doutorados e Sul - 3 mestrados e 1 doutorado. Criados em diferentes momentos, embora tendo muitos aspectos comuns, os cursos podem ser divididos, de uma forma geral, em cursos que fazem parte de grandes instituições voltadas exclusivamente para a Saúde Pública - ou seja, as faculdades e escolas de Saúde Pública; estarem localizados no interior de faculdades de Medicina, geralmente nos departamentos de Medicina Preventiva e Social; serem parte integrante de complexos institucionais denominados institutos, de Saúde Coletiva ou de Medicina Social; ou delimitarem determinadas temáticas, como Saúde da Criança, Saúde da Mulher, Epidemiologia, Planejamento em Saúde.

Sem dúvida, essa estrutura concorre para a existência tanto de cursos gerais, sem áreas de concentração, como os que já se organizam com diversas áreas de concentração, ou os que já surgem definindo uma determinada área ou temática.

Dentre os muitos aspectos que podem ser tratados sobre os cursos de pós-graduação, escolhemos o da análise da estrutura curricular, que foi, inclusive, objeto da avaliação realizada pela ABRASCO sobre a pós-graduação. Não vamos detalhar todos os aspectos levantados, mas trazer algumas informações que evidenciam como o campo de ensino vem-se estruturando. Foram classificados os conteúdos curriculares do mestrado e do doutorado de 17 cursos de mestrado e 9 de doutorado.

No mestrado, há 38 áreas de concentração, sendo que $49 \%$ dos conteúdos foram incluídos nas Ciências da Saúde, com maiores concentrações em: Saúde Coletiva $(90,2 \%)$ e na subárea de Epidemiologia $(40,9 \%)$, Planejamento e Administração em Saúde (27,3\%) e Bioestatística (23,6\%); 44,1\% em Ciências Humanas, sendo que na área de Filosofia, Metodologia é a subárea com maior concentração (75\%), seguida da Epistemologia $(22,9 \%)$.

As três outras grandes áreas de conhecimento, que somam cerca de 7\% dos conteúdos, são: Ciências Biológicas; Ciências Exatas e da Terra e Ciências Sociais Aplicadas. O doutorado irá repetir a mesma estrutura encontrada no mestrado, com as seguintes porcentagens: no doutorado, há 28 áreas de concentração, sendo que 45,6\% dos conteúdos foram incluídos em Ciências da Saúde, com maiores concentrações em: Saúde Coletiva $(88,9 \%)$ e na subárea 
de Epidemiologia (52\%), Bioestatística (28,6\%) e Planejamento e Administração em Saúde (14,3\%); 44,9 em Ciências Humanas, sendo que, na área de Filosofia, a Metodologia é a subárea com maior concentração $(67,7 \%)$, seguida da Epistemologia $(25,8 \%)$. As três outras grandes áreas de conhecimento somam $9,5 \%$ dos conteúdos restantes ministrados no doutorado.

Como foi bem salientado por Minayo (1997, p. 62):

\begin{abstract}
"Quanto à estrutura curricular, o incremento das disciplinas de caráter filosófico e metodológico e uma grande diversidade de objetos e temáticas, de um lado, evidenciam pujança da área; de outro, revelam problemas de delimitação no âmbito dos saberes e práticas, e dispersão significativa nos modelos de organização dos cursos. Enfim, constata-se uma excessiva liberdade na elaboração dos conteúdos e das ementas disciplinares, sugerindo, ao lado da expressão criativa dos professores/ pesquisadores/ orientadores, dificuldades de demarcação técnica da formação".
\end{abstract}

A estrutura atual, embora demonstre claramente o caráter interdisciplinar da área, evidencia que nem sempre certas disciplinas importantes no campo biológico e das ciências aplicadas, das Ciências Ambientais, da Demografia e da Economia têm sido contempladas nos planos de ensino. Em sua abalizada avaliação dos cursos, Minayo (1997, p. 63) aponta que tem havido o superdimensionamento de certos conhecimentos e a atrofia de outros:

"tais dinâmicas acontecem a partir de várias lógicas, desde as mais pragmáticas, como a disponibilidade de docentes, até as influenciadas por reações ideológicas, a exemplo da que supervalorizou as questões sociais e políticas na formação, em detrimento de outros aspectos, nas duas últimas décadas”.

Segundo alguns estudiosos, dever-se-ia valorizar mais a história intelectual da saúde pública.

Frente à grande diversidade que conforma o campo da Saúde Coletiva e à tendência de especialização em torno de áreas disciplinares (por exemplo: Antropologia da Saúde) ou de temáticas (por exemplo: Saúde Materno-Infantil) e ao fato de que a demanda é de caráter multiprofissional, algumas questões têm sido debatidas. Dentre elas, a de que não se deveria abrir mão de um núcleo comum de conhecimento para formar mestres e doutores. Para alguns, a própria diversidade impediria de imaginar a possibilidade de conhecimentos gerais e integradores; para os que são favoráveis, o núcleo comum seria 
fundamental para preservar a identidade da área. A questão é delimitar esse núcleo de conhecimentos, pois, para uns, seria formado por conteúdos de Ciências Sociais, Epidemiologia e Planejamento; para outros, estaria assentado na discussão de temas no campo da Filosofia da Ciência e da Metodologia Científica ou, ainda, da História da Saúde Pública, como forma de garantir a preservação de um certo ideário sanitarista. No caso do curso de pós-graduação em Saúde Coletiva da UNICAMP, no doutorado é ministrada a disciplina História e Paradigmas do Conhecimento em Saúde, que exemplifica essa busca de fornecer aos doutorandos uma visão global da Saúde Coletiva e de seus principais campos.

Considerando que o currículo é produto da própria concepção de Educação, e muitas são essas concepções, não se pode descolar a estrutura curricular dos objetivos que norteiam a idéia de um curso de Saúde Coletiva. Nisso, certamente, incluem-se, como escreve Von Buettner (1990), os interesses humanos subjacentes aos modelos de currículos a serem adotados, e que podem ser de três espécies: técnico, consensual e emancipador. Embora não seja nosso interesse desenvolver esses modelos, lembramos que a autora identifica três grandes enfoques de pesquisas utilizados na construção do currículo: o empíricoanalítico; o histórico-hermenêutico e o praxiológico, propondo três paradigmas de currículos: o técnico-linear, o circular-consensual e o dinâmico-dialógico, que são importantes na delimitação do ensino na área da Saúde Coletiva.

\section{Perspectivas}

Não detalharemos pontos já abordados, mas desejamos fazer algumas considerações que parecem pertinentes. Uma delas diz respeito ao perfil da demanda dos cursos. Percebe-se, na atualidade, a tendência de ingressar nos cursos um número maior de profissionais vindos dos serviços de saúde, com perfis profissionais bastante diversificados, pois anteriormente predominavam pessoas das universidades e institutos de pesquisa.

Outro ponto é a crescente especialização do campo, que cria áreas de concentração. A própria organização curricular e a produção específica dos cursos (dissertações e teses) evidenciam não somente a amplitude da área, como sua extrema diversificação. A diversificação em grandes áreas coloca continuamente para os especialistas do campo questões que não podem ser marginalizadas. Uma delas refere-se ao objeto central - a saúde: complexo, polissêmico, mulitifacetado -, cuja abordagem, embora respeitando-se a 
especificidade com que se deseja olhá-lo, não pode prescindir de uma visão global que o contextualize num plano mais geral.

Minayo (1997, p. 59-60), em seu brilhante trabalho de avaliação da pós-graduação, aponta, dentre outras, duas reflexões que são aqui retomadas e das quais compartilhamos. A primeira é sobre a relação entre o progresso econômico e suas repercussões sociais:

"A visão do campo da Saúde Coletiva é que o progresso econômico deve estar a serviço da eqüidade, e a ciência e tecnologia relacionadas a um projeto de desenvolvimento ancorado no caráter dinâmico dos processos avaliativos de prioridades. Ou seja, sob qualquer aspecto que se analise, essa área de conhecimentos e de práticas não se coloca à margem do desenvolvimento da biologia, da genética, das ciências ambientais, da medicina. Porém vincula esses avanços a seu sentido social, político e de direito universal".

Outra reflexão é que "a área reveja o seu discurso bastante reduzido ao universo das doenças e ancorado em análises macrossociais sobre os determinantes da saúde", num esforço de articulação das diferentes áreas do conhecimento já mencionadas ${ }^{4}$.

Ao concluírem seu estudo sobre a saúde coletiva, Paim e Almeida Filho (1998, p. 312) assinalam:

\footnotetext{
"apesar de preencher as condições epistemológicas e pragmáticas para se apresentar, em si mesma, como um novo paradigma científico, a saúde coletiva se consolida como campo científico e âmbito de práticas aberto à incorporação de propostas inovadoras, muito mais do que qualquer outro movimento equivalente na esfera da saúde pública mundial”.
}

Chamam a atenção para a complexidade do objeto - promoção-saúdeenfermidade-cuidado:

"que só se define em sua configuração mais ampla, já que tem facetas, ângulos distintos e a mirada de cada um destes ângulos não nos dá acesso à integralidade deste objeto", que denominam de "integrais de saúde-enfermidade-cuidado"(PAIM e ALMEIDA FILHO, 1998, p. 312).

Retomando outra idéia por eles desenvolvida, reproduzimos um longo trecho que nos parece bastante instigante e que nos interessa, na medida em 
que trabalhamos aqui com as práticas pedagógicas e científicas:

"No âmbito dos processos de reprodução (ensino/formação) da Saúde Coletiva enquanto campo de conhecimento com facilidade reconhece-se o potencial da fractalidade como princípio organizador do seu âmbito de práticas. Por um lado, em uma perspectiva dialética, a prática da saúde coletiva será 'minimalista' e localizada e ao mesmo tempo holística e globalizante. Por outro lado, em uma perspectiva pragmática, a Saúde Coletiva enquanto âmbito de práticas se constituirá em um permanente processo de autocriação, balizada primordialmente pelos seus efeitos concretos sobre a realidade de saúde".

A fim de atender a essas posturas, os autores sugerem uma pauta de ação que atenda à qualificação das necessidades sociais em saúde, não apenas como carências, mas como ideais, projetos de vir-a-ser; pense os meios e as atividades necessárias para atender a tais necessidades; instaure novas relações técnicas e sociais, como os processos de distritalização, muncipalização, educação etc.; invista política e tecnicamente nos espaços institucionais, redefinindo as práticas de Saúde Coletiva.

Ao finalizar este texto, destacamos que nossa posição em relação à Saúde Coletiva é a de que ela se fundamenta na interdisciplinaridade como possibilitadora da construção de um conhecimento ampliado da saúde, no qual continuam presentes os desafios de trabalhar com as dimensões qualitativas e quantitativas, sincrônicas e diacrônicas, objetivas e subjetivas. Assim, não existe a possibilidade de uma única formulação teórica e metodológica quando espaço, tempo e pessoa não são simplesmente variáveis, mas constituem parte integrante de processos históricos e sociais.

\section{Referências}

AROUCA, A. S. S. O dilema preventivista: contribuição para a compreensão e crítica da medicina preventiva. 1975. Tese (Doutorado em Saúde Coletiva)Faculdade de Ciências Médicas, Universidade Estadual de Campinas, Campinas, 1975.

ASSOCIAÇÃO BRASILEIRA DE PÓS-GRADUAÇÃO EM SAÚDE COLETIVA (ABRASCO). Documento Preliminar de Princípios Básicos. In: Ensino da Saúde Pública, Medicina Preventiva e Social no Brasil. Rio de 
Janeiro: Nutes/Clates, 1982. p.109-117.

BADGLEY, R. F. Salud pública: tendencias y desafios. In: La crisis de la salud pública: reflexiones para el debate. Washington: OPAS, 1992. (Publ. Cient. n. 540). p. 57-73.

BELISÁRIO, S. A. Associativismo em saúde coletiva: um estudo da Associação Brasileira de Pós-Graduação em Saúde Coletiva - ABRASCO. 2002. Tese (Doutorado em Saúde Coletiva)-Faculdade de Ciências Médicas, Universidade Estadual de Campinas, Campinas, 2002.

BEZERRA JR., B.; SAYD, J. Um mestrado para um momento preciso. Rio de Janeiro: UERJ/IMS, 1993. (Estudos em Saúde Coletiva, 47).

BIRMAN, J. A physis e a saúde coletiva. Physis: Revista de Saúde Coletiva, v. 1, n. 1, p. 7-11, 1991.

BOURDIEU, P. O campo científico. In: ORTIZ, R. (org.). Pierre Bourdieu: sociologia. São Paulo: Ática, 1983.

BRAGA, J. C.; PAULA, A. G. Saúde e previdência: estudos de política social. São Paulo: Hucitec, 1981.

BURLANDY, L. Saúde coletiva: uma trajetória em questão. Refletindo sobre a produção científica no campo das políticas de saúde (1979-1991). 1993. Dissertação (Mestrado em Saúde Pública)-Escola Nacional de Saúde Pública/ Fiocruz, Rio de Janeiro, 1993.

CAMPOS, G. W. S. Saúde pública e saúde coletiva: campo e núcleo de saberes e práticas. Ciência \& Saúde Coletiva, Rio de Janeiro, v. 5, n. 2, p. 219-250, 2000.

CARVALHO, A I. Da saúde pública às políticas saudáveis: saúde e cidadania na pós-modernidade. Ciência \& Saúde Coletiva, Rio de Janeiro, v. 1, n. 1, p. 104-121, 1996.

CARVALHO, M. A. R. A institucionalização das ciências sociais brasileiras e o campo da saúde. In: CANESQUI, A. M. (org.). Ciências sociais e saúde. São Paulo: Hucitec, 1997. p. 49-67.

COC/FIOCRUZ. Carlos Chagas (1879-1934). Disponível em < $\underline{\text { http:// }}$ www.fiocruz.br/coc/fioch1.html>. Acesso em: 10 maio 2005.

DONNANGELO, M. C. F. Medicina e sociedade: o médico e seu mercado 
de trabalho. São Paulo: Pioneira, 1975.

FERREIRA, J. R. La crisis. In: La crisis de la salud pública: reflexiones para el debate. Washington: OPAS, 1992. (Publ. Cient. n. 540). p. 233-236.

FOUCAULT, M. O nascimento da Medicina Social. In: . Microfísica do poder. Rio de Janeiro: Graal, 1979.

FRENK, J. La nueva salud pública. In: La crisis de la salud pública: reflexiones para el debate. Washington: OPAS, 1992. (Publ. Cient. n. 540). p. 75-93.

GUÉRIN, J. Médicine Sociale: au corps médicale de France. Gazette Médicale de Paris, Paris, 11 mar.1848. p. 183.

HOBSBAWN, E. A era do capital: 1848-1875. Rio de Janeiro: Paz e Terra, 1979.

LAURELL, A. C. El estudio del proceso salud-enfermedad en América latina. Cuadernos Médico-Sociales, v. 17, n. 3, p. 3-18, 1986.

LUZ, M. T. As instituições médicas no Brasil: instituição e estratégia de hegemonia. Rio de Janeiro: Graal, 1979.

. Medicina e ordem política brasileira: políticas e instituições de saúde (1850-1930). Rio de Janeiro: Graal, 1982.

MACEDO, C. G. El contexto. In: La crisis de la salud pública: reflexiones para el debate. Washington: OPAS, 1992. (Publ. Cient. n. 540). p. 237-242.

MACHADO, R.; LOUREIRO, A.; MURICY, K. Danação da Norma: medicina social e constituição da psiquiatria no Brasil. Rio de Janeiro: Graal, 1978.

MEHRY, E. E. Saúde Pública como política: um estudo dos formuladores de políticas. São Paulo: Hucitec, 1992.

MINAYO, M. C. S. Pós-Graduação em Saúde Coletiva: um projeto em construção. Ciência \& Saúde Coletiva, Rio de Janeiro, v. 2, n. 1/2, p. 53-71, 1997.

NUNES, E. D. Medicina social: origens e desenvolvimentos. Revista de Cultura Vozes, Petrópolis, v. 74, n. 3, p.173-198, 1980.

NUNES, E. D. A questão da interdisciplinaridade no estudo da saúde coletiva e o papel das ciências sociais. In: CANESQUI, A M. (org.) Dilemas e desafios 
das ciências sociais na saúde coletiva. São Paulo:Hucitec; Rio de Janeiro:ABRASCO, 1995. p. 95-113.

. Saúde coletiva: história de uma idéia e de um conceito. Saúde e Sociedade, São Paulo, v. 3, n. 2, p. 5-21, 1994.

. Trayectoria de la medicina social en América Latina: elementos para su configuración. In: FRANCO, S.; NUNES., E. D.; BREILH, J. \& LAURELL, A C. (orgs.). Debates en medicina social. Washington: OPAS, 1991.p. 17-137.

NUNES, E. D.; COSTA, P. S. Os cursos de saúde coletiva no Brasil - mestrado e doutorado: um estudo sobre as disciplinas básicas. Ciência \& Saúde Coletiva, Rio de Janeiro, v. 2, n. 1/2, p. 72-90, 1997.

ORGANIZACIÓN PANAMERICANA DE LA SALUD. Ensenãnza de la Medicina Preventiva y social: 20 años de experiencia latinoamericana. Washington: OPAS/OMS, 1976, p. 43.

PAIM, J. S.; ALMEIDA FILHO, N. Saúde coletiva: uma "nova saúde pública" ou campo aberto a novos paradigmas?. Revista de Saúde Pública, São Paulo, v. 32, n. 4, p. 299-316, 1998.

PERLIN, L. I. Strucuture and meaning in medical sociology. Journal of Health and Social Behavior, Albany, v. 33, p. 1-9, 1992.

ROSEN, G. The evolution of social medicine. In: FREEMAN, H. E.; LEVINE, S. \& REEDER, L. G. (eds.). Handbook of medical sociology. New Jersey: Prentice-Hall, 1963, p. 18-51.

SALOMON-BAYET, C. Pasteur et la révolution pastorienne. Paris: Payot, 1986.

SCHRAMM, R. A terceira margem da saúde: a ética natural: complexidade, crise e responsabilidade no saber fazer sanitário. 1993. Tese (Doutorado em Saúde Pública)- Escola Nacional de Saúde Pública/Fiocruz, Rio de Janeiro, 1993.

STOTZ, E. N. A saúde coletiva como projeto científico: teoria, problemas e valores na crise da modernidade. In: CANESQUI, A. M. Ciências sociais e saúde. São Paulo: Hucitec, 1997. p. 273-284.

SUSSER, M. \& SUSSER, E. Choosing a future for epidemiology: eras and 
paradigms. American Journal of Public Health, v. 56, n. 5, p. 668-673, 1996. TEIXEIRA, S. M. F. As ciências sociais em saúde no Brasil. In: NUNES, E. D. (org.). As ciências sociais em saúde na América Latina: tendências e perspectivas. Brasília: OPAS, 1985. p. 87-109.

TEIXEIRA, S. M. F. O dilema da reforma sanitária. In: BERLINGUER, G.; TEIXEIRA, S. M. F.; CAMPOS, G. W. S. Reforma sanitária Itália e Brasil. São Paulo: Hucitec, 1988. p. 195-207.

TERRIS, M. Tendencias actuales en la salud pública de las Américas. In: La crisis de la salud pública: reflexiones para el debate. Washington: OPAS, 1992 (Publ. Cient. n. 540). p. 185-204.

TESTA, M. Salud pública: acerca de su sentido y significado. In: La crisis de la salud pública: reflexiones para el debate. Washington: OPAS, 1992 (Publ. Cient. n. 540). p. 205-229.

VON BUETTNER, G. E. B. P. Análise da estrutura curricular de um curso de Psicologia: subsídios para a reestruturação. 1990. Dissertação (Mestrado em Educação)-Faculdade de Educação, Universidade Estadual de Campinas, Campinas, 1990.

YIDA, M. Saúde pública: reprodução ou legitimação. 1988. Tese (Doutorado em Saúde Pública)-Faculdade de Saúde Pública, Universidade de São Paulo, São Paulo, 1988.

\section{NOTAS}

* Doutor em Ciência; professor associado de Ciências Sociais em Saúde e Saúde Coletiva do Departamento de Medicina Preventiva e Social da Faculdade de Ciências Médicas da Universidade Estadual de Campinas. Endereçco eletrônico: evernunes@uol.com.br.

${ }^{1}$ Outras características do campo são dadas pelo autor: "Campo científico é um sistema de relações objetivas entre posições adquiridas que, conquistadas pelos agentes em lutas anteriores, concorrem pelo monopólio de uma espécie particular de capital: a legitimidade ou autoridade científica [...]". Ou seja, concorrem pelo poder de impor os critérios que definem o que é e o que não é científico". Um campo, portanto, é uma esfera da vida social que se foi automatizando progressivamente através da história em torno de um certo tipo de relações sociais, de interesses e de recursos próprios, diferentes de outros campos. Dessa forma, o grau de autonomia de um campo científico se torna básico e pode ser medido das seguintes formas: 1) no poder de que 
dispõe esse campo para definir as normas de sua produção; 2) nos critérios de avaliação de seus produtos; 3) na legitimidade para reinterpretar as determinações externas, a partir de seus próprios princípios de funcionamento. Para o autor, o entendimento de campo supõe o de espaço social, entendido como um sistema de posições sociais que se definem umas em relação às outras (autoridade/súdito, chefe/subordinado, patrão/empregado, homem/mulher, rico/pobre, erudito/popular), constituindo um sistema de diferenças sociais hierarquizadas ("a distinção") em função de um sistema de legitimidades socialmente estabelecidas e reconhecidas em um momento determinado.

${ }^{2}$ Os fatores incluídos em cada categoria são os seguintes: Biologia Humana - envolve todos os fatos que se manifestam como consequiência da constituição orgânica do indivíduo, incluindo sua herança genética e seus processos de maturação; Ambiente - agrupa os fatores externos ao organismo, em suas dimensões física e social, sobre os quais o indivíduo exerce pouco ou nenhum controle; Estilo de vida - o conjunto das decisões que o indivíduo toma a respeito de sua saúde, no que se refere, por exemplo, a suas atividades de lazer e alimentação, estando portanto parcialmente sob seu controle; Organização da Atenção à Saúde - disponibilidade, quantidade e qualidade dos recursos destinado aos cuidados com a saúde (CARVALHO, 1997, p 106).

${ }^{3}$ Recente avaliação dos Programas de Mestrado e Doutorado assinalou: "1. Do ponto de vista conceitual, embora se observe um aprimoramento na definição de área de concentração, linhas e projetos de pesquisa, vários programas revelam dificuldades na sua compreensão e referência. Por vezes, as denominações de linhas referem-se a disciplinas propriamente ditas ou a áreas temáticas, não se configurando em temas/problemas de investigação que agreguem vários projetos. Nesse sentido, é freqüente a superposição de dissertações/tese e projetos (quando não linhas) de pesquisa. Isso provavelmente explica a opção, de alguns programas, relatarem discentesautores como responsáveis por projeto (que, se não equivocado, deve representar raras exceções); ${ }^{4}$ Reafirma-se que a constituição de uma área de concentração depende da existência de pessoal qualificado para a formação de 'especialistas' na área respectiva” (CAPES. Documento de área, agosto de 2002). 


\section{ABSTRACT}

Graduate Studies in Collective Health in Brazil: History and Prospects

This study approaches the establishment of the field of Collective Health in Brazil in three dimensions: the origins of Collective Health, historical aspects of health in Brazil, and Collective Health as a pedagogical practice, as well as prospects for the field. The underlying notion in the elaboration of this study considers Collective Health as a field, within the concept proposed by Pierre Bourdieu. The author presents information on the situation with graduate courses and the curricular structure. The conclusions demarcate the view of Collective Health as a field based on interdisciplinarity and the quantitative and qualitative, synchronous and diachronic, and objective and subjective dimensions.

Key words: Collective Health, history; Collective Health, pedagogical practice; Collective Health, curricular structure. 